\title{
Integration of cloud based eCare services: a Multidisciplinary Challenge
}

\author{
Frederic \\ Vannieuwenborg \\ Dept. of Information \\ Technology \\ Ghent University - iMinds \\ Ghent, Belgium \\ Frederic.Vannieuwenborg \\ @intec.ugent.be
}

\author{
Jan Van Ooteghem \\ Dept. of Information \\ Technology \\ Ghent University - iMinds \\ Ghent, Belgium \\ Jan.Vanootghem \\ @intec.ugent.be
}

\author{
Femke Ongenae \\ Dept. of Information \\ Technology \\ Ghent University - iMinds \\ Ghent, Belgium \\ Femke.Ongenae \\ @intec.ugent.be
}

\author{
Stijn Verstichel \\ Dept. of Information \\ Technology \\ Ghent University - iMinds \\ Ghent, Belgium \\ Stijn.Verstichel \\ @intec.ugent.be
}

\author{
Sofie Verbrugge \\ Dept. of Information \\ Technology \\ Ghent University - iMinds \\ Ghent, Belgium \\ Sofie.Verbrugge \\ @intec.ugent.be
}

\begin{abstract}
Due to changes in the demographic situation of most Western European countries, interest in ICT supported care services grows fast. eCare services are believed to be cost-effective and could lead to an increased quality of life of both care receiver and (in)formal care giver. Currently adoption and integration of these services is slowed down by several barriers such as an unclear added value, a lack of regulations or a sustainable financial model. In order to understand the interactions between political, market related and technological forces, as sources of these barriers, collaboration between all actors involved in eCare service development (user and technological research groups, care organizations, technological partners, techno-economic research groups, etc. ) is needed. In this paper various tools and methodologies, applied in the iMinds OCareClouds project, are discussed that foster collaboration and allow identification and understanding of the different forces.
\end{abstract}

\section{Keywords}

Smart home care platform, eCare services, service integration and adoption, multidisciplinary approach

\section{INTRODUCTION}

Changes in healthcare policies can be noticed in EU-member states in order to deal with the demographic challenges. Also, general interest in ICT supported care applications (eCare services) like remote fall detection applications [2], social contact enhancing applications, etc. grows exponentially [7]. Although their impact has not always been proven yet, many researchers and care givers see these applications as tools to improve the quality of care while reducing the cost of care.

OCareClouds (OCCS) is a cloud based smart home care platform (SCP) [4], allowing integration, monitoring and data exchange between a set of home care service applications (e.g. life style monitoring, (in)formal data sharing application) that run on the central OCCS platform.

The goal of these eCare services is to improve the quality of life for the patient while reducing the current cost for long-term home care. The OCCS platform allows exchanging information between the care receiver and his or her (in)formal caregivers, or between the caregivers reciprocally. Furthermore, the integration of various sensors in the homes of care receivers that monitor some specific variables of their habits (room temperature, movement of the person, bed detection, etc.) [3] allows longitudinal analyses that can provide meaningful insights in evolution of the condition of the care receivers.

Permission to make digital or hard copies of all or part of this work for personal or classroom use is granted without fee provided that copies are not made or distributed for profit or commercial advantage and that copies bear this notice and the full citation on the first page. To copy otherwise, to republish, to post on servers or to redistribute to lists, requires prior specific permission and/or a fee.

IDPHA 2014, May 20-22

Copyright $\odot 2014$ ICST 978-1-63190-011-2

DOI 10.4108/icst.pervasivehealth.2014.255783
Like most other eCare and eHealth services, the introduction of these OCCS services faces various barriers for a smooth integration and adoption [1]. Following barriers are identified: 1) an unclear financing model, 2) lack of policies and regulations, 3) lacking support of care givers, 4) evidence of impact is unclear, 5) lack of standardization for data exchanging [11], 6) unclear return on investment for care providers or organisations, 7) added value for care receivers is not always clear and 8) there is no cultural acceptance and support.

Addressing those barriers in advance to the extent possible is of utmost importance to guarantee a durable and viable business case. In this work methodologies, used in the OCareClouds project, are presented that result in the formulation of eCare services that are supported by users, service developers and accordant to national policies.

\section{SHAPING THE INTEGRATION PATH}

In general every service available on the market is a result of interactions of two or three forces. The three main forces are entitled as 1) the market force, 2) the technological force and 3) the political force [5]. Each service is driven by one of these forces but impacts one or two other forces. It is important to identify and understand the impact on each of these forces in order to be able to formulate a solid business case.

\subsection{Market forces}

As the name suggests, market forces result from the total population or specific subset of it which have a clear need or formulate a demand for a particular service of which the perceived added value could improve the business as usual. Both qualitative (social) and or quantitative (economic) reasons can be the basic of this need or demand.

Most Western European countries face similar demographic changes. An aging population is the proof of progress in medical care and improved societal security systems but results at the same time in some social challenges such as an increased pressure on the complete care system because of the higher need for care.

Topics like the need for quality of life (QoL) improvement and active aging at home are now trending because of these approaching challenges. With this, also the interest and demand for ICT supported care services grows since they are believed to be cost effective measures to (partially) tackle the challenges resulting of the growing number of elderly people [6]. This can be seen as the demand for eCare services driven by the market forces.

\subsection{Technological forces}

It is true that recognizing the needs of the market or detecting added values for it does not always occur by asking users for it. In 
most cases potential users lack the capability to imagine the real impact of changing the business as usual. Therefore forcing the market and creating a need is an often used strategy of the industry (technology push).

But although there exists success stories of products and services (e.g. SMS) where no one was really waiting for initially, pure technology push does not guarantee business success. This is certainly the case when it comes to eCare services which typically require user interaction and acceptance.

\subsection{Political forces}

Both technological and market forces can be impacted by political forces. Policies can stimulate or slow down the adoption and integration of new services.

Of particular interest for eCare services are legalizations and policies (or the lack of them) on privacy, ownership of health related data, data interchangeability and reimbursement.

Often political forces are seen as innovation killers but there exist also plenty of examples where they are the driving forces for integration. Examples are for instance the reduction of the number of hospital beds and inpatient care facilities, the requirement for digital drug prescriptions, reimbursement for new health technologies, financial incentives for care facilities who meet specific quality standards, etc.

\subsection{User research and techno-economics as keys to understand force interactions}

Plenty of research is available that examines the role of supplydemand, technology push versus demand pull or the impact of market, technological and political forces [8]. There is no need to address this topic again. This work wants to focus how to deal with these forces in a methodological way in order to formulate viable business cases for eCare services.

Key aspects in linking the different forces are techno-economic modeling and user research. In the OCareClouds project, the techno-economic focus is on identifying different market strategies based on the cost benefits when integrating eCare services (services of interest are sharing (in)formal care data, automatic rescheduling of caregivers when there is a change in the care schedule and automated billing processes [10]).

User research on the other hand investigates the attitude towards eCare service integration of the care receivers (elderly people in need of care and living at home) and their care givers (both formal and informal caregivers). Through an iterative co-creation process, user researchers could identify interesting and less interesting services for the users, based on their formulated needs or perceived value of eCare services. Figure 1 gives a schematic overview of the different market forces and their interactions.

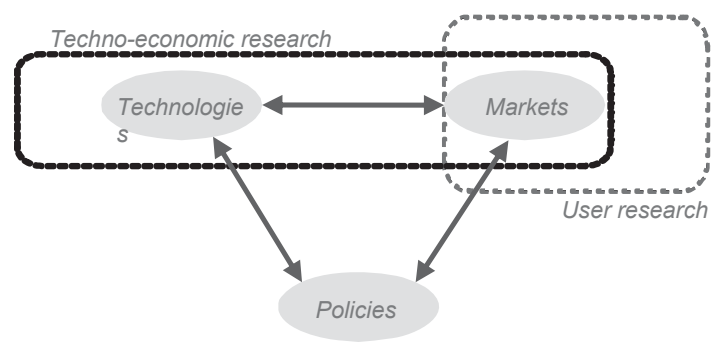

Figure 1: Shaping the integration path: interaction of forces[5]
As said in 3.1, the market forces can be subdivided in both social and economic forces. Users not only must like the service or experience it as value adding, also a willingness to pay from the end user is needed. Often these aspects go hand in hand. But this is not always the case for care related services or products. Because of the well developed and deployed social care and care insurance systems in Western Europe people tend to correlate care with being paid by the government or low private contributions. Also many elderly people do not enjoy a wealthy pension and need the money for medication or medical care. These financial aspects results in additional challenges for formulating potential market strategies.

\section{USED APPROACHES}

In the beginning of the OCCS project, the ontology research engineers and industrial partners within the consortium (technological forces) had a strong vision on what they wanted to develop (Life style monitoring (e.g. movement, room temperature, hours TV per day, etc.) and a shared care data record) even before there was a good understanding of the market.

From interviews with users, user researchers concluded that the added value for elderly and (in)formal caregivers for this type of service is not clear at all. Also care organizations formulated clear adverse statements on the added value for them and their employees.

Later on, from interviews with care organizations and care service providers, potential value streams for them were identified and mapped upon the technological proposals and vice a versa.

Through a continuous interaction of the several forces whether or not guided by the different forces themselves or the user and techno-economic research groups, agreement on the eCare services of interest for both demand pull and technology push sides was obtained. Several tools and methodologies are used to nurture these interactions. Most important ones are: the Techcards mapping tool, process decomposition, Interdisciplinary cocreation workshops, innovation binder meetings and integration meetings.

\subsection{Tools for interdisciplinary collaboration}

\subsubsection{Tech-cards mapping}

In a technological project in which various technical partners are involved together with non-technological people such as economists and user groups (e.g. care organisations) clear communication on the technology developed is required in order to be able to understand the value network and points of impact with current existing systems such as the back office systems of care organizations.

Tech card mapping is a methodology used to communicate over the different technological components and there various interactions. A tech card is a one pager that summarizes the functionalities of the technical component, the development status and ownership of it and the interactions it has with preceding and following components. The figure below is an example of a tech card used in the OCCS project.

Chaining or mapping the different tech cards provide insights in the complete technological status of the project and allows nontechnical people to understand the flow of the processed data and resulting actions. 


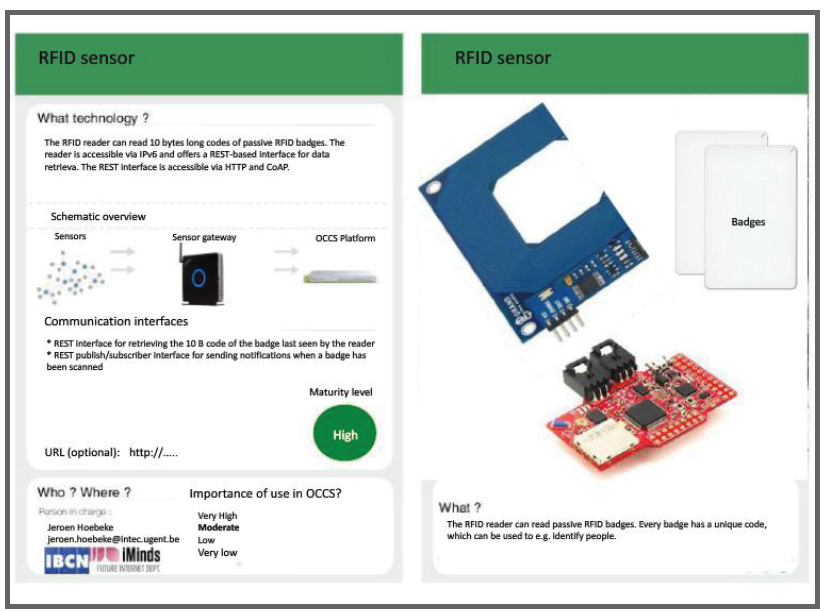

Figure 2: Example of a tech card of the RFID hardware component

\subsubsection{Interdisciplinary co-creation workshops}

Bringing all the involved project partners together to participate and contribute in a prepared workshop on a certain topic is of great importance to broaden up the perspective of the models and to gain insights in real life situations.

A workshop is not a brainstorm session but a test of the assumptions against real life situations and leads to adaptations of the models accordant to the user feedback.

Within the OCareClouds project there several workshops were organized. A first workshop was on detecting the added value and potential barriers for users. A second workshop was on completing the value network needed for offering eCare services. Integrating new eCare services requires new roles and responsibilities of actors not directly involved in care provisioning (e.g. the platform provisioning and maintenance, hardware installation and service education, etc.). These new roles need to be assigned to particular actors. In order to gain knowledge in those new value network configurations, actors pointed out which role they see fulfilled by which actor.

A final planned workshop will focus on different market entry strategies. Several market strategies are identified but each strategy implies different investments and resources gains for different actors. In order to be able to check the business potential of each strategy they need to be checked by various care experts and instances.

Throughout the project different workshops on technologies were organized as well. Examples are for instance a decision tree workshop [9]. The OCCS platform takes decisions based on monitoring input (e.g. room temperature, movement, etc.) or user input (e.g. care schedules, (in)formal care data, etc.). A platform decision must lead to appropriate care actions such as informing a particular (in)formal care giver. In order to model the various decisions and conditions, input is needed from both direct users such as elderly people and their informal care givers and the care organisations.

\subsubsection{Innovation binder meetings}

In the OCCS project, the two weekly consortium meetings are named innovation binder meetings. These meetings are initiated from the user research groups involved in the project. Their goal is to check whether the technological progresses are still in line with the overall targets of the integration of eCare services.

Essential tools are the future user scenarios. These are short fictive care scenarios based on real case in which the integration of eCare services is included. These scenarios are further subdivided in numerous scenes such as: the care giver logs in on the OCCS platform.

Reflections on these scenes identified practical challenges and conformity checks with the technological implementations. In short; these meetings translate the practical usage of the services to technological implementations (e.g. the employee of a care organizations logs in on the OCCS platform, therefore that person takes his or her NFC-enabled smart phone and swipes it at the table in which an NFC reader is integrated).

\subsubsection{Integration meetings}

The previously described tech-cards mapping method leads to a theoretical chain of interacting soft-and hardware components. In order to bring these interactions into practice, conventions have to be agreed upon. Not only data format is an example but also the way these interactions are put into practice (e.g. REST calls, etc.) Since various partners ranging from sensor integrators to care service developers integration meetings are the basis for a streamlined data exchange process.

Direct input from non-technical partners is not required in this step since it focuses on pure technological integration.

\subsubsection{Process decomposition}

A technological overlay on existing care processes leads to changes in resources used. Integrating eCare services requires investments and potentially leads to increased efficiency (e.g. reduced costs, higher throughput, etc.) or qualitative improvements such as higher quality of life for the care receiver.

To get a complete understanding of all impacted care process building blocks (all steps required to deliver care at home e.g. transport to the care receiver, delivering care, care scheduling, communication with other (in)formal care givers, billing, etc.) decomposing current care processes (AS IS process) and composing the care process with the new technological impacts (TO BE process) is required. This basically comes down to performing a business as usual assessment and comparing it with a modeled futuristic process.

This two step approach allows detecting changes in the current care processes and resources used which is the basic for the economic model. Input from stakeholders involved is needed for the TO BE process compositions in order to achieve streamlined processes that are realistic and in accordance with the capabilities of the user organizations (a TO BE process can make sense from a technological perspective but can be impossible to implement by the care organisations). Figure 3 is an example of a TO BE process formulation and indicates which care process building blocks are impacted by the integration of technology and its impact in resources used. Starting from the scenes in the user scenario (first line), a care process decomposition was performed. Potential impacted care service building blocks were identified and a description of the total impact was provided. In the last line, technological components to realise this $\mathrm{TO} \mathrm{BE}$ scenario were linked with the care process building blocks. 


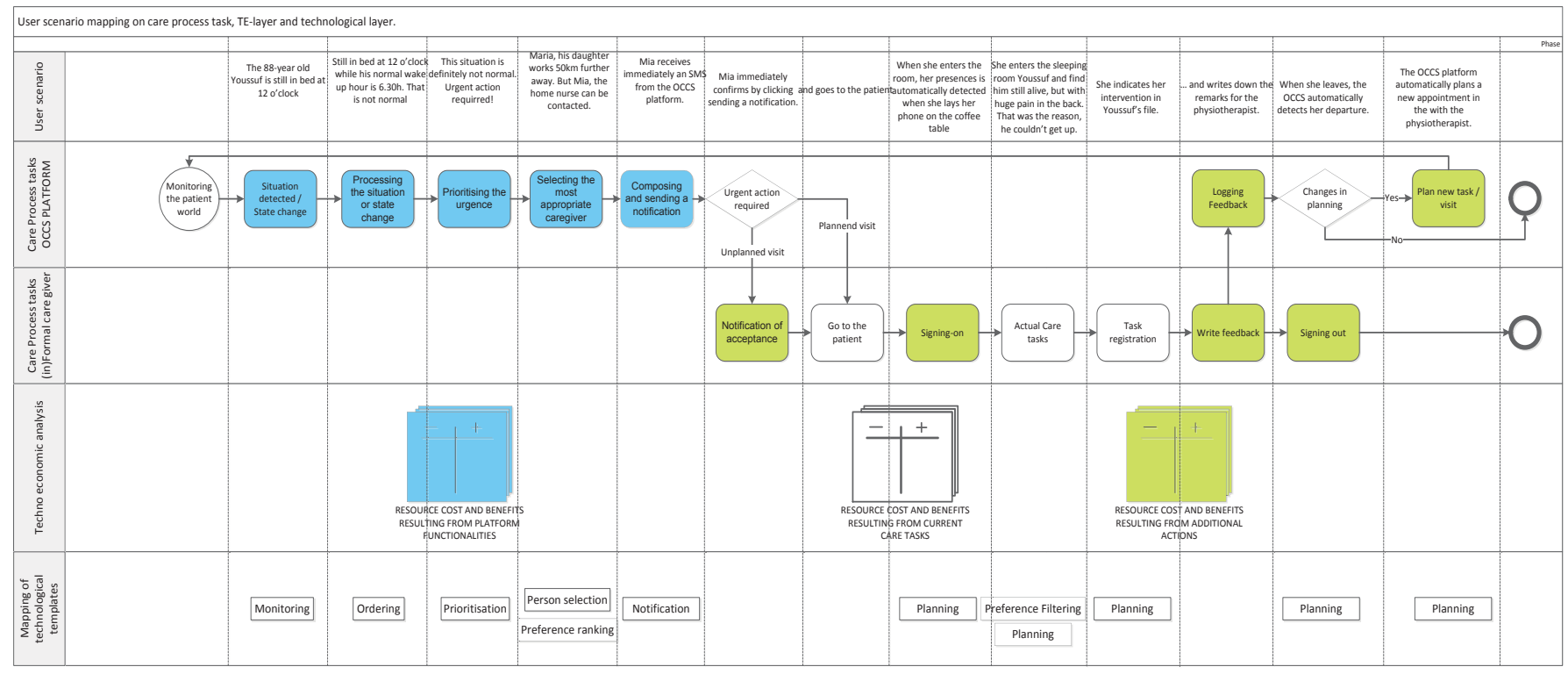

Figure 3: Example of process decomposition

\subsection{Pros and cons of used methodologies}

Not all methodologies are applicable in all phases of the project. For instance integration meetings should be held at the beginning of the project to determine the standards and at the end, to practically integrate the developed solutions. Co-creation workshops should be performed throughout the complete project to validate the models, assumptions and approaches.

Most of the above described tools enhance cooperation and active engagement of all partners involved in the OCareClouds project; technological partners, user- and research groups. But some methodologies tend not to be that relevant or well understood by some involved partners. In what follows a summarization of the pros and cons of the different methodologies is presented. They were detected throughout the complete project.

Tech-cards mapping (Technical perspective):

+ Tech-cards mapping allows visualizing the technological process steps and their mutual impacts

+ if done at an early stage of the project, potential overlapping interests or lack of technological knowledge can be detected - It is sometimes too difficult for non-technical people to understand the various technical components

- Tech card mapping seems to be the most valuable for technical people only

Interdisciplinary co-creation workshops (Social \& Technoeconomic perspective):

+ Opens new perspectives and allows validation of the developed models, services, artefacts, etc. test the created models

+ Allows direct feedback from the involved partners

+ Active involvement of the users makes it interesting to participate

+ Can be done at every stage of the project timeline in order to update the current models

+ Participation is accessible and should not require specific upfront knowledge. Personal preparation for the topic can be needed.

- Requires much time to prepare the workshop and to inform/educate participants on the topic
- Results of a workshop can differ a lot from the expected output. This makes the outcome of a workshop not always easy to use.

Innovation binder meetings (Social perspective):

+ Consortium meetings on a regular basis keep the research focused on the agreed targets and the people involved.

- All people around the table should pay attention that the topic of the meeting is not on, or tend to shift to technological issues. Non -technical members of the consortium just lose their time when discussions are on technical details.

Integration meetings (Technical perspective):

+ Bringing together several technological partners in order to discuss on the integration of their components can lead to clear goals and targets.

+ Parallel integration of the components at the same time often leads to productive time investments and speeds up the progress of the project

- This type of meetings is only valuable for specific technological actors which need to collaborate on one or more domains.

Process decomposition (Social, Technical \& Techno-economic perspective):

+ Identification of impacts on current care processes and the change in resource consumption caused by the integration of eCare services.

+ Tool allows discussion on the current way of providing care - Every actor (social, technological or techno-economic) has to use the same definitions for all functionalities and care and service buildings blocks.

\section{SUMMARY}

Successful integration of eCare services is very challenging due to several barriers such as unclear added value for the users, financial barriers, technological barriers, different economic interests, etc.

Understanding the various interactions between the market, political and technological forces allows better service definitions and business case formulation. In order to capture, nurture and deal with these interactions from the three forces, collaboration 
and involvement of both technological partners (technological research groups and industrial partners) and user groups (user research groups and care organizations) is ensured through the use of the tools and methodologies that foster interdisciplinary cocreation. This work provides an overview of five different approaches and their pros and cons, used within the OCCS project.

\section{ACKNOWLEDGMENTS}

This research work was partially supported by the Concerted Research Actions grant for the research project: "High Potential Entrepreneurship and entrepreneurial value creation: context influences, context interactions and context extension" (project code 01G03011) from the Ghent University and the NBB, National Bank Belgium. We acknowledge that part of this research was also supported by the iMinds Project OCareCloudS co-funded by the IWT, the iMinds and the following partners: Televic Healthcare, TPVision, Telecom IT and Boone NV. We would also like to thank OCMW-Kortrijk, OCMW-Ghent and Familiehulp for their cooperation in the project The author of this publication also has received funding from the Agency for Innovation by Science and Technology in Flanders (IWT).

\section{REFERENCES}

[1] (2012, 5 april). Barrieres voor opschaling Ehealth. Available: http://www.ehealthnu.nl/barrieres

[2] F. De Backere, F. Ongenae, F. Van den Abeele, J. Hoebeke, S. Verstichel, A. Ackaert, and F. De Turck, "Social-aware and context-aware multi-sensor fall detection platform," in Workshop on Semantic Web Applications and Tools for Life Sciences (SWAT4LS-2013), 2013, pp. 1-4.

[3] H. Gokalp and M. Clarke, "Monitoring Activities of Daily Living of the Elderly and the Potential for Its Use in Telecare and Telehealth: A Review," TELEMEDICINE and eHEALTH, vol. 19, pp. 910-923, 2013.

[4] iMinds vzw. (2014, February, 2014). OCareCloudS (Organizing care with trusted, cloud-like services). Available: http://www.iminds.be/en/research/overviewprojects/p/detail/ocareclouds-2

[5] W. H. Melody, "State of the Art: Regulatory Priorities 2007."

[6] I. Meyer, S. Müller, L. Kubitschke, A. Dobrev, R. Hammerschmidt, W. Korte, T. Hüsing, T. van Kleef, S. Otto, and J. Heywood, "eCare as a Way of Coping With an Ageing Population-Today and Tomorrow. The eCare Benchmarking Study," Technical Report, European Commission, Directorate General Information Society and Media, Brussels2013.

[7] E. V. Mora, M. Lluch, I. Casas, F. Abadie, and I. Maghiros, "Towards Integrated Personal Health and Care Services deployment in Europe," IVWorkshop on, 2012.

[8] G. F. Nemet, "Demand-pull, technology-push, and government-led incentives for non-incremental technical change," Research Policy, vol. 38, pp. 700-709, 2009.

[9] F. Ongenae, L. Bleumes, N. Sulmon, M. Verstraete, M. Van Gils, A. Jacobs, S. De Zutter, P. Verhoeve, A. Ackaert, and F. De Turck, "Participatory design of a continuous care ontology: towards a user-driven ontology engineering methodology," in International conference on Knowledge Engineering and Ontology Development (KEOD 2011), 2011, pp. 81-90.

[10] F. Ongenae, "Ontology design and management for eCare services," Ghent University, 2013.
[11] F. Vannieuwenborg, J. Van Ooteghem, A. Ackaert, S. Verbrugge, D. Colle, and M. Pickavet, "Towards a national platform for personal medical data sharing," presented at the eChallenges 2012, Lisboa, Portugal, 2012. 